УДК 633.511:631.

https://doi.org/10.32634/0869-8155-2022-355-1-78-82

Краткий обзор/Brief review

\section{Оруджава Р.Н.}

Азербайджанский государственный аграрный университет, г. Гянджа, Азербайджанская Республика

E-mail: qehremanova1977@mail.ru

Ключевые слова: почва, агрогенное воздействие, техногенное воздействие, дренаж плодородие, пористость, засоление, ирригационное засоление, ландшафт

Для цитирования: Оруджава Р.Н. Краткое описание возникновения антропогенной трансформации земель в Азербайджане, виды и особенности антропогенных воздействий. Аграрная наука. 2022; 355 (1): 78-82.

https://doi.org/10.32634/0869-8155-2022-355-1-78-82

Конфликт интересов отсутствует

Ramala N. Orujova

Azerbaijan State Agricultural University, Ganja, Azerbaijan

E-mail:qehremanova1977@mail.ru

Key words: soil, agrogenic impact, technogenic impact, drainage, fertility, porosity, salinity (brackish soil), irrigation salinization of the landscape

For citation: Orujova R.N. Briefly about the emergence of anthropogenic land transformation in Azerbaijan, types and characteristics of anthropogenic impacts. Agrarian Science. 2022; 355 (1): 78-82. (In Russ.)

https://doi.org/10.32634/0869-8155-2022-355-1-78-82

There is no conflict of interests
Краткое описание возникновения антропогенной трансформации земель в Азербайджане, виды и особенности антропогенных воздействий

\section{РЕЗЮМЕ}

Изучение антропогенного преобразования земель в Азербайджане началось с изучения направлений изменений орошаемых земель. Исследования показывают, что при игнорировании законов почвы и экологии антропогенные воздействия приводят к тому, что земли в Азербайджане, как и везде на Земле, подвергаются разной степени деградации. Бесконтрольный и интенсивный выпас скота на высокогорных и среднегорных участках, на границах летних пастбищ с лесами привел к снижению верхних границ лесов, усилению эрозионных процессов, половодий и паводков. Деградация почв во многих регионах Азербайджана, в том числе на Джейранчельской равнине, создала важные экономические, биологические, экологические и другие проблемы. На основании проведенных исследований было установлено, что около 80\% земельных ресурсов Азербайджана подверглись природной и антропогенной деградации в некоторой степени.

\section{Briefly about the emergence of anthropogenic land transformation in Azerbaijan, types and characteristics of anthropogenic impacts}

\section{ABSTRACT}

The study of the anthropogenic transformation of land in Azerbaijan began with the study of the directions of changes in irrigated lands. Studies show that when ignoring the laws of soil and ecology, anthropogenic influences lead to the fact that the lands in Azerbaijan, as elsewhere on earth, are subjected to various degrees of degradation. Uncontrolled and intensive grazing of cattle on high and medium mountain areas, on the borders of summer pastures with forests, has led to a decrease in the upper borders of forests, increased erosion processes, high water and flash flooding. Soil degradation in many regions of the Azerbaijan, including the Jeyranchol plain, has created important economic, biological, environmental, and other problems. Based on the conducted research, it was determined that about $80 \%$ of the land resources of Azerbaijan have been subjected to natural and anthropogenic degradation to some extent. 


\section{Введение}

В качестве примера непосредственного воздействия человека на природу можно привести исчезновение лесов на обширных территориях, чрезмерное истребление охотничьих животных. Это приводит к резкому сокращению ряда видов, а во многих случаях и к их полному исчезновению. Опосредованные антропогенные факторы возникают путем изменения ландшафта климата, физического состояния и химического состава атмосферы, гидросферы, почвы и др. Это приводит к загрязнению окружающей среды промышленными и бытовыми отходами, нарушению экологического равновесия, деградации биоценозов (групп организмов), сформированных в результате эволюции на протяжении тысячелетий. Люди, повышая плодородие почв, на месте природных комплексов создали практически новую среду обитания для культурных растений и домашних животных, новые группировки организмов - агробиоценозы.

Интенсивная вспашка земель и чрезмерный выпас скота, вырубка осушительных лесов поставили в тяжелое положение природные группировки в ряде районов, усилили водную и ветровую эрозию, сократили водный поток рек [2].

В настоящее время на Земле едва ли можно встретить область, не подверженную деятельности человека. Огромное влияние человека на природу и его негативные последствия поставили перед человечеством необходимость осуществления научно обоснованных мероприятий по сохранению и рациональному использованию богатств биосферы [3].

Почва, как и другие составляющие ландшафта, постоянно подвергается антропогенным воздействиям Эти эффекты можно разделить на два типа по характеру. Первое - агрогенное воздействие; второе - техногенное воздействие. В исследовании эти воздействия были оценены по-разному. Агрогенные воздействия это мероприятия по обработке почвы, повышению плодородия и урожайности. Некоторые из воздействий связанных с этим, можно рассматривать как специализированные воздействия.

Эти воздействия включают в себя проведение постоянных и последовательных возделываний при выполнении вспашки, применение минеральных и органических удобрений, использование препаратов различного состава против вредителей и болезней культурных растений, проведение орошения, выпас на пастбищах. Часть агрогенных воздействий носит временный характер Они включают в себя мелиорацию, глубокую вспашку в определенные периоды времени, строительство дренажа, ирригационных арык-каналов, использование мелиорантов различного назначения и т.д.

\section{Методика опыта}

Исследования показывают, что антропогенные воздействия при игнорировании почвенных и экологических законов приводят к тому, что почвы, как и везде на Земле, подвергаются различным степеням деградации. Неконтролируемый и интенсивный выпас скота в высоких и средних горных районах, на границах летних пастбищ с лесами привел к понижению верхних границ лесов, усилению эрозионных процессов, половодий и паводков. Деградация почв во многих регионах республики, в том числе на Джейранчольской равнине, создала важные экономические, биологические, экологические и др. проблемы. На основании проведенных исследований установлено, что около 80\% земельных ресурсов республики в той или иной степени подверглось естественной и антропогенной деградации [4].

Процесс деградации более характерен для зимних пастбищ Джейранчольской равнины, которая является объектом исследования. Основная причина деградации на этой территории связана с вырубкой лесов, уничтожением растительности и чрезмерным выпасом скота вдоль реки Кура [5].

Многообразие техногенных воздействий влияет на количественные и качественные показатели почвы и приводит к ее трансформации в более радикальных формах. Ликвидация последствий техногенных воздействий не только сложна, но и требует больших финансовых ресурсов. Примером этих воздействий могут служить разведка, добыча и транспортировка полезных ископаемых, пожары, проведение военных действий, строительство дорог, градостроительные работы, озеленение городов и их окрестностей и т.д. Они отличаются друг от друга по интенсивности антропогенных воздействий на почву. В результате этого по интенсивности антропогенных воздействий в ходе исследований их можно разделить на слабые, умеренные и тяжелые типы. Потому что на всех территориях интенсивность антропогенных воздействий на почвы неодинакова.

Это влияние варьируется в зависимости от зоны расположения почвы, ее использования и показателей плодородия [6].

Последствия антропогенных воздействий очень разнообразны, как и направления воздействий. Последствия агрогенных воздействий в основном обратимы, а техногенных - очень сложны и земли не поддаются восстановлению. В результате вспашки почвы нарушаются ее верхние горизонты и усиливается процесс аэрации почвенной массы в пахотном слое в зоне распространения корней, так как вспашка осуществляется преимущественно тяжелыми тракторами, искусственный нижний слой затвердевает. Если этот процесс повторится несколько раз, то затвердевание посадочного субстрата еще более усиливается, нарушается структурный состав в пахотном слое почвы без вспашки и сухой обработки. При вспашке элементарный процесс почвообразования изменяется незначительно.

При первом размещении многолетних насаждений проводят глубокую (преимущественно 60-70 см) вспашку, перемешивают почвенную массу, в результате чего структура почвы механически разрушается, изменяется пористость, появляется изменчивость воздушно-влажностного режима. При глубокой вспашке изменчивость более отличается при элементарном процессе почвообразования. Результат этого процесса проявляется в течение нескольких лет. Как известно, это приводит к возникновению антропогенной трансформации [7].

Применение минеральных и органических удобрений при возделывании способствует повышению органического состава верхнего горизонта почвы и увеличению общей порции питательных элементов. В отличие от верхнего горизонта, который формирует антропогенную трансформацию почвы, создавая питательную среду для растений. Во многих случаях это приводит к химическому загрязнению почвы. Длительное применение удобрений приводит к тому, что содержание тяжелых металлов в почве превышает допустимые пределы, потому что в составе минеральных удобрений концентрируются достаточное количество вредных тяжелых металлов. Превышение допустимого 
содержания тяжелых металлов в почвах сказывается на применении лекарственных средств или пестицидов различного состава, применяемых для защиты культурных растений. Это практикуется многократно во многих случаях и они накапливаются в почве до опасных пределов. Это приводит к изменению химического состава верхнего (0-50 см) слоя почвы. Проведение ирригации и оросительных работ в условиях аридного климата оказывает более дифференцированное и несколько направленное влияние на развитие антропогенной трансформации почв. По этим характеристикам их отождествляют с техногенными факторами орошения. Для организации полива проводится много земляных работ. Возникает необходимость в строительстве оросительных арык-каналов, проведении земляных работ. Эти процессы происходят в почве, вызывая ее изменение.

Орошаемые почвы отличаются разнообразием поверхностных наклонностей. Наклонность является одним из основных факторов в орошении и трансформации почв. Показатели наклонности в нашей области исследования весьма разнообразны. Повышение наклона способствует развитию ирригационной эрозии.

На слабо наклонных почвах скопление оросительной воды может просачиваться и сливаться с грунтовыми водами, вызывая повторное засоление или ирригационное засоление.

Полив резко нарушает элементарный процесс почвообразования, основная причина чего - нарушение гидротермического режима. В летний период - в период вегетации растений - температура воздуха составляет, как известно, 30-35 ${ }^{\circ} \mathrm{C}$, а на поверхности почвы температура в это время поднимается до $60^{\circ} \mathrm{C}$. В это время температура воды, поступающей в почву, не поднимается выше 25-26 ㄷ. При каждом поливе на каждый гектар почвы подается 900-1200 м³ водной массы. Указанные процессы влияют на структурный состав почвы, температурно-воздушный режим, микробиологическую активность. Поступление в почву внезапно большой массы воды усиливает ее внутреннюю эрозию. Известно, что источники орошения разнообразны, так же разнообразны и показатели их состава.

Полив вызывает изменение морфологической структуры почвы. Эти изменения не проходят без влияния на толщину отдельных горизонтов, их физические, водно-физические свойства, гумус, толщину горизонта, количество и состав гумуса.

Движение воды в почве в зависимости от гидравлики потока переносит мелкие частицы в горизонтальном направлении и перемешивает почвенную массу с поверхностной. Этот процесс транспортирует воду и содержащиеся в ней почвенные соединения к концу поля и создает изменения и преобразования на поверхности, которые привлекают внимание. Эти почвенные смеси в первую очередь влияют на гранулометрический состав, так что механизм его возникновения зависит от свойств почвы. На наклонных участках наблюдаются резкие различия между верхней и нижней частью орошаемого участка. Масса воды с созданием поверхностного потока также просачивается вдоль его профиля. В процессе просачивания вода аккумулирует в нижних горизонтах мелкие частицы и растворенные в ней биогенные элементы, соли, гумусы и другие вещества и элементы [8].

Орошение создает деферементацию солености почвы внутри участков. Этот процесс оказывает большее влияние на микрорельеф поверхности. Также важным фактором здесь является количество солей, содержащихся в поливной воде. Количество и содержание солей в поливной воде зависит от источника воды. Основным источником поливной воды в целом по Азербайджанской Республике являются речные воды и подземные воды. Как мы уже отмечали ранее, выпас скота играет важную роль в антропогенной трансформации пастбищ. Перегрузка пастбищ на территории Азербайджанской Республики еще больше интенсифицирует этот процесс.

Вместе с поливной водой в почву поступают ценные элементы и вещества. Эти элементы и вещества положительно влияют на плодородие почвы. В первую очередь они оседают в водорастворимых и илистых материалах. Одним из основных показателей поливной воды является ее мутность.

Артезианские воды в исследуемых нами районах не мутные, а реки и магистральные каналы в основном мутные. Мутность в реке Куре 2,28 г/л, в Шамкирском канале этот показатель 2,88 г/л. В Гошгарчае этот показатель составил 0,56 г/л, а в реке Гянджа - 0,48 г/л. Известно, что мутные воды богаты ценными питательными веществами. Плодородие земель, орошаемых этими водами, высокое. Анализы показывают, что пробы из родниковой воды содержат гумус, азот, фосфор и другие биогенные элементы. Количество гумуса в осадках, полученных из реки Куры, составило 1,48\%, а в осадках Шамкирского канала несколько меньше - 1,31\%. Этот показатель значительно меньше наблюдается в водах Гошгарчай и Гянджачай.

Исследования показывают, что азот содержится во всех водах. Если в водах реки Куры и Шамкирского канала его содержание составляло 0,23-0,21\%, то в остальных пробах воды этот показатель был сравнительно невелик и в основном составлял 0,10-0,14\%. Содержание фосфора в воде источников орошения на исследуемой территории колеблется в пределах 0,230,32\%. Наибольшее количество было 0,32\% в реке Кура и Шамкирском канале, а наименьшее - 0,23\% в так называемом кустарном источнике 1 в селе Агасибейли. Количество $\mathrm{K}_{2} \mathrm{O}$ достаточно велико и составляет 2,47-3,37 мг/кг.

Артезианская вода характеризуется высокой минерализацией, которая колеблется в основном от 2,01 до 2,99 г/л, в речных водах этот показатель не превышает 1,22-1,41 г/л, оросительные воды Самухского района преимущественно щелочные. В кустарных водах $\mathrm{pH}$ 7,9-8,2, в речных 7,3-7,8.

Поливная вода также содержит $\mathrm{NH}$ и $\mathrm{NO}_{2}$. Количество $\mathrm{NH}_{4}$ составляет в основном 0,01-0,03 мг/л, а количество $\mathrm{NO}-$ 0,03-0,06 мг/л. Лабораторный анализ показывает, что в поливной воде обнаружен фенол. Содержание его в речной воде относительно высокое, 0,37-0,42 мг/л. В артизанской воде оно не выше 0,18-0,22 мг/л.

Даже на участке, где мы проводили исследование, пастбища перегружены сверх нормы и осуществляотся неупорядоченный выпас скота. Работы по выпасу скота приводят прежде всего к уплотнению верхнего горизонта почвы, разрушению дернового слоя и, воздействуя на характер поверхностного потока, создают его трансформацию.

В результате техногенных воздействий в последние годы в нашей стране от экосистемы отделились большие участки земли. Главным образом горнодобывающая деятельность, расширение градостроительных поселений, создание садов и парков изменили коли- 
чественные и качественные показатели антропогенной трансформации почв от техногенных воздействий. В номенклатуру вошли новые названия, в частности стал массовым термин «урбанизм». В Азербайджане в этом направлении ведутся хоть и небольшие, но исследовательские работы. Однако эта работа проводится только на территории города Баку.

В Азербайджане после второй половины прошлого века интенсивность техногенных процессов возросла. В эти годы увеличилась добыча полезных ископаемых, расширилась их география, и все больше земель вышло из сельскохозяйственного использования по мере трансформации.

Для расширения орошаемых земель строились водохранилища, магистральные каналы. Это привело к тому, что большие земельные участки пришли в негодность.

При проведении фундаментальных мелиоративных работ, выравнивания поверхности почвы, при строительстве дренажей и каналов произошла мелиоративная деградация почв, особенно в Кура-Аразской низменности, что привело к антропогенной трансформации.

Изучение антропогенной трансформации земель в Азербайджане началось с изучения направлений изменения орошаемых земель. Но история антропогенных воздействий на почвы начинается очень давно. Так, древнегреческий географ Страбон, живший еще в III веке до нашей эры, в своей книге «География» писал, что в Албании (современный Азербайджан) на землях, прилегающих к рекам Кура и Араз, было развито орошаемое земледелие, сопоставимое с земледелием Древнего Египта и Месопотамии. В последующие периоды сохранились достаточно ценные сведения о развитии орошаемого земледелия в отдельных частях Кура-Аразской низменности. В частности в разные периоды истории на почвах оккупированных стран были разрушены оросительные системы и эти земли стали малопродуктивными пастбищами.

В XIII веке во время нашествия монголов в Азербайджан были разрушены и выведены из строя почти все оросительные системы, а также сеть арык-каналов на всей территории Азербайджана, которые строились в течение многих предыдущих лет.

На Гянджа-Газахской равнине, где мы проводили исследования, и на землях Самухского района, являющихся его частью, были выведены из строя системы орошения, в том числе созданные в те времена источники обеспечения водой - кахризы. Многие из этих кахризов на сегодняшний день вышли из строя, но некоторые были восстановлены и приведены в работоспособность. На месте этих кахризов во второй половине прошлого века были пробурены артезианские скважины.

Гянджа-Газахская наклонная равнина является вторым после Кура-Аразской низменности регионом с развитым орошаемым земледелием. Здесь влияние богарного земледелия на почву гораздо больше и в то же время разностороннее [9]

Животноводство в Азербайджане имеет очень древнюю историю, в том числе его развитие связано с ирригационным земледелием. Это не нуждается в доказательствах. В основном было развито кочевое скотоводство, большая часть земель, используемых в современном орошаемом земледелии, была зимними пастбищами. Но влияние на пастбища имеет совсем иной характер по сравнению с земледелием, и его роль в трансформации почвы слабая.
За последние 50-60 лет преобразование пастбищ в пахотные земли и поселения интенсивно повлияло на его антропогенную трансформацию. [10].

По многим субъективным причинам уменьшились площади пастбищных угодий, а количество животных, наоборот, увеличилось. Из-за этого пастбищные земли подвергаются большей нагрузке. Эти влияния стали более ярко проявляться в антропогенной трансформации почв. Нерегулярность выпаса скота привела к затвердеванию почв, интенсификации процессов эрозии и дефляции, что в конечном итоге привело к антропогенной трансформации и потере плодородия. Из приведенного выше объяснения видно, что почвы, распространенные на территории Азербайджанской Республики, в том числе на территории Гянджа-Газахской наклонной равнины, исторически и в настоящее время трансформировались под антропогенным воздействием, изменились показатели плодородия и почвенных процессов.

Изучением антропогенной трансформации почв в Азербайджане начал заниматься Бабаев М.П. в 60-70-е годы прошлого века. Он впервые провел экспериментальные исследования в области влияния орошения на почвы. Он в своих исследовательских материалах показал трансформации, происходящие в результате оросительных работ, на серо-бурых, лугово-серых, серых почвах различных частей Кура-Аразской низменности. Он также разделил почвы на древние орошаемые, орошаемые и новые орошаемые типы, основываясь на их морфологических и морфометрических признаках при классификации в соответствии с историей развития орошения. Здесь были показаны различия в трансформациях, происходящих в почве в соответствии с этим разделением. Он экспериментально доказал изменчивость, вызванную антропогенными изменениями в физическом состоянии и химическом составе орошаемых почв, а также изменениями в солончаковатых и солонцеватых почвах.

Исходя из антропогенной трансформации, исследователь определил плодородие почв.

Начиная с 90-х годов прошлого века под руководством Бабаева М.П. в этом направлении было проведено много исследовательских работ. В основном в 2000-х годах Э.А. Гурбанов исследовал процесс трансформации земель Кура-Аразской низменности в результате оросительно-мелиоративных работ, показал эрозионный процесс, происходящий при орошении, и его влияние на морфологические, химические и физические свойства почв. Также большое значение имеют его исследования в области возникновения изменчивости в почве при выпасе скота, ускорения процессов эрозии и дефляции и, в общем, большое значение имеет его исследовательская работа по деградации почв.

В указанном направлении существуют экспериментальные работы М.Г. Мустафаева, В.Х. Хасанова, Б. Ибрагимова и многих других исследователей.

\section{Результаты}

Почва, как и другие составляющие ландшафта, постоянно подвергается антропогенным воздействиям. Эти эффекты можно разделить на два типа по характеру. Первый - это агрогенные воздействия, а второй - техногенные. Эти воздействия были оценены по-разному в зависимости от направления исследований. Агрогенные воздействия - это мероприятия, предпринимаемые для обработки почвы, повышения плодородия и урожайности. Некоторые из воздействий, связанных с этим, можно рассматривать как специализированные 
воздействия. Эти воздействия включают в себя проведение постоянных и последовательных возделываний при выполнении вспашки, применение минеральных и органических удобрений, использование препаратов различного состава против вредителей и болезней культурных растений, проведение орошения, выпас на пастбищах. Часть агрогенных воздействий носит временный характер.

\section{ЛИТЕРАТУРА}

1. Алиев И.Г. «Государственная программа социально-экономического развития регионов Азербайджанской Республики на 2019-2023 годы. Баку, 29 января 2019 года. [ Aliev I.G. "State program of socio-economic development of the regions of the Republic of Azerbaijan for 2019-2023. Baku, January 29, 2019]

2. Вердиева В.Г., Гусейнов М.С., Деградация пастбищных почв Азербайджана из-за перевыпаса скота и пути их улучшения // Международный научный журнал, Наука и мир, № 9 (13), Волгоград, 2014, с. 46-48.

3. Бабаев А.X. Разработка комплекса мер по борьбе с деградацией почвенного покрова на территории Джейранчоля // Научно-практическая конференция на тему «Направления развития аграрной науки и ее экологические аспекты». Гянджа-2009, с. 2. [Babaev M.P. Development of a set of measures to combat soil degradation in the territory of Jeyranchol // Scientificpractical conference on the theme "Trends in the development of agricultural science and its environmental aspects." Ganja-2009, p. 2.]

4. Мамедов Г.Ш. Социально-экономические и экологические основы эффективного использования земельных ресурсов Азербайджана. Баку: Элм, 2007, 856 с.[ Mamedov G.Sh. Socio-economic and environmental foundations for effective use of land resources of Azerbaijan. Baku: Elm, 2007, 856 p.]

5. Вердиева В.Г., Деградация почв Азербайджанской республики и пути их улучшения. / Актуальные вопросы и тенденции развития в современной науке. Материалы международной научно-практической конференции. Махачкала, 30 мая, 2014 , c. $10-15$

\section{ОБ АВТОРАХ:}

Оруджова Рамала Набил кызы, докторант, ассистент кафедры общего земледелия, генетики и селекции

\section{Выводы}

Анализ показывает, что в Самухском районе орошаемые земли содержат достаточно смесей. Эти химические соединения неизбежно могут повлиять на преобразование почв. За каждый вегетационный период в почву поступает в среднем 600 м $^{3}$ воды, что способствует накоплению в почве большого количества минералов и биогенных элементов и ее преобразованию.

6. Бабаев М.П., Гасанов В.Х., Джафарова. Ч.М., Гусейнова С.М., Морфогенетическая диагностика, номенклатура и классификация почв Азербайджана. Баку: Элм, 2011, 452 с.[ Babaev M.P., Khasanov V.Kh., Jafarova. Ch.M., Huseynova S.M., Morphogenetic diagnostics, nomenclature and classification of soils in Azerbaijan. Baku: Elm, 2011, 452 s]

7. Гусейнов А.М., Гусейнов Н.В. Химия почвы. Баку. 2015 , 584 c.[ Guseinov A.M., Guseinov N.V. Soil chemistry. Baku. 2015, 584 p.]

8. Вердиева В.Г., Экологическая оценка деградированных почв / Информационные технологии в экономике, образовании и бизнесе. Материалы VII международной научно-практической конференции, Саратов, 2014, с. 43-46.

9. Оруджова Р.Н. Антропогенная трансформация некоторых генетических особенностей серо-бурых почв Гянджа-Казахской наклонной равнины / Сборник научных новостей Азербайджанского Технологического Университета. Гянджа, 2020. c. 120-126. [ Orujova R.N. Anthropogenic transformation of some genetic features of gray-brown soils of the Ganja-Kazakh sloping plain / Collection of scientific news of the Azerbaijan Technological University. Ganja, 2020. p. 120-126.]

10. Вердиева В.Г. Изучение агрохимических показателей деградированных светло-серо-бурых (светло-каштановых) почв в массиве Джейранчоль / Собрание сочинений АТК, том 14, Баку-2016, с.433-436. [Verdieva V.G. Study of agrochemical indicators of degraded light gray-brown (light chestnut) soils in the Jeyranchol massif / Collected Works of ATK, Volume 14, Baku2016, pp. 433-436.]

\section{ABOUT THE AUTHORS:}

Ramala Orujova, PhD student, Assistant of the General Agriculture, Genetics and Breeding Department

\section{НОВОСТИ•НОВОСТИ•НОВОСТИ•НОВОСТИ॰}

\section{В России с 2022 года реализуется новая госпрограмма эффективного вовлечения в оборот земель сельхозназначения}

Вопросы устойчивого землепользования, его влияние на продовольственную безопасность обсудили участники 14-ой Берлинской конференции аграрных министров, прошедшей 27 января в рамках Глобального Форума по продовольствию и сельскому хозяйству (GFFA). Россию на мероприятии представил заместитель министра сельского хозяйства РФ Сергей Левин.

Сохранение, восстановление и повышение плодородия почв - это первостепенные задачи развития АПК РФ, отметил замминистра. В России применяется широкий комплекс мер, направленных на их решение. В частности, с 2022 года реализуется новая госпрограмма эффективного вовлечения в оборот земель сельхозназна- чения. Помимо этого, аграриям оказывается поддержка по известкованию кислых почв и по приобретению минеральных удобрений. Также, добавил чиновник, развивается государственный мониторинг земель и создаются специализированные информационные ресурсы, содержащие сведения об их состоянии и плодородии.

Сергей Левин акцентировал внимание на активном участии РФ в глобальных инициативах по данному направлению. Наша страна оказывает значительную поддержку Глобальному почвенному партнерству с момента его учреждения в 2012 году, а в конце прошлого года на продолжение финансирования инициативы Правительством РФ было принято решение о выделении до 2 млн долл., сообщил он.

Россия также способствовала учреждению Всемирного дня почв, Международного года почв и Всемирной почвенной премии имени российского ученого-почвоведа Глинки. 